MEMÓRIA

\title{
A trajetória do Instituto Butantan: pesquisa e produção de imunobiológicos para a saúde pública
}

Luiz Antonio Teixeira*

Na última década do século XIX, o Estado de São Paulo desenvolvia-se rapidamente. Os recursos provenientes do café favoreciam a criação de ferrovias, indústrias e serviços. Além disso, a lavoura cafeeira transformava-o num grande polo de atração de imigrantes, fazendo sua população ampliar-se rapidamente. No entanto, esse desenvolvimento era o motor do surgimento de diversas crises epidêmicas, principalmente de febre amarela e varíola. Com a Constituição republicana de 1891, as questôes de saúde se tornaram competência dos governos estaduais. Essa reforma permitiu que o Estado de São Paulo iniciasse, no ano seguinte, a implantação de um amplo sistema de saúde pública direcionado ao combate às doenças epidêmicas (BENCHIMOL; TEIXEIRA, 1994).

No âmbito do novo sistema de saúde - então chamado de Serviço Sanitário de São Paulo -, surgiram diversos institutos que trabalhavam no diagnóstico para o controle de doenças epidêmicas. Nesse período a microbiologia despontava como principal aliada da saúde pública no combate a doenças transmissíveis, sendo a base de grande parte dos trabalhos desenvolvidos nesses centros. Dos institutos de pesquisas surgiam vacinas para proteger contra diversas epidemias, soros para curar os atingidos e exames diagnósticos para certificar os médicos das medidas a serem empregadas. O Butantan foi uma das instituiçôes de pesquisas criadas no Estado de

* Pesquisador da Casa de Oswaldo Cruz/Fundação Oswaldo Cruz, Rio de Janeiro (RJ), Brasil. E-mail: teixeira@fiocruz.br 
São Paulo em virtude dessa reforma. Seu surgimento, em 1900, foi consequência de um surto de peste bubônica no Porto de Santos em 1899. Para combatê-lo, o governo do Estado convocou o médico Vital Brasil (1865-1950), pesquisador do Instituto Bacteriológico. Em Santos, ele encontraria o médico Oswaldo Cruz, enviado pelo governo federal para a mesma função que Vital cumpria no Estado de São Paulo. Do encontro dos dois nasceria uma parceria, importante para criação e desenvolvimento dos dois institutos que em pouco tempo surgiriam.

Consolidado o diagnóstico em Santos, Vital Brasil montou um laboratório para produzir vacina antipestosa. De forma semelhante, Oswaldo Cruz foi encarregado pelo governo do Distrito Federal de, juntamente com o barão de Pedro Afonso, criar um instituto antipestoso no Rio de Janeiro. Em 1900 surgia o Instituto de Manguinhos que, em pouco tempo, passou para a direção única de Oswaldo Cruz. No ano seguinte, o laboratório criado por Vital Brasil tornar-se-ia uma instituição autônoma com o nome de Instituto Soroterápico de São Paulo. Ambas instituições seriam de grande importância para a saúde pública. A correspondência entre Vital Brasil e Oswaldo Cruz, datada de $1899,{ }^{1}$ mostra a relação de cooperação entre os dirigentes das duas instituiçóes que simultaneamente começavam a dar um novo horizonte ao combate às doenças infecciosas e ao desenvolvimento da pesquisa biomédica no Brasil.

Construído numa fazenda no distante bairro do Butantã, o laboratório dirigido por Vital Brasil passou a ser conhecido pelo nome da região que o abrigava. O período que se seguiu à criação marcou seus anos heroicos, momento em que, lutando contra uma crônica falta de recursos, seus pesquisadores conseguiram colocar de pé a instituição, centrando sua pesquisa no campo do ofidismo e produzindo soros contra picada de serpentes. Esse período se estendeu até 1914, quando foi concluída sua nova sede. No entanto, foi no final da década de 1910 que ocorreram as maiores transformaçôes na trajetória do Instituto. Em 1916, o médico baiano Arthur Neiva passou a dirigir a saúde pública paulista, procurando estender ao interior do Estado as atividades de saúde que até então se restringiam aos centros urbanos. Para alcançar esse objetivo, ele tentou ampliar as funções do Butantan, transformando-o na base da saúde pública para produção de medicamentos para as endemias que assolavam o interior do Estado. Assim, o Instituto também passou a ter como atividades o estudo e cultivo de plantas medicinais, a produção de medicamentos para a saúde

1 Correspondências entre Oswaldo Cruz e Vital Brasil. Dossiê Vital Brazil - 1899/1914 - Acervo Departamento de Arquivo e Documentação, Fundação Oswaldo Cruz, Casa de Oswaldo Cruz. 
pública e a fiscalização dos soros e vacinas utilizados em São Paulo (BENCHIMOL; TEIXEIRA, 1994).

Apesar dos esforços, o projeto de ampliação do Butantan não prosperou. Ele entrou em colapso em 1919, quando Vital Brasil deixou o Instituto. Sua saída detonou uma grave crise, pois, além de alguns pesquisadores o acompanharem, seu principal auxiliar, João Florêncio Gomes (1886-1919), especialista em biologia e sistemática de ofídios e já convidado para substituí-lo, faleceu antes de ingressar no cargo. A falta de profissionais para dar continuidade às pesquisas e à produção fez com que as atividades do Instituto se reduzissem (BENCHIMOL; TEIXEIRA, 1994).

A crise disparada no Butantan pela saída de seu diretor tinha como um dos principais componentes o difícil equilíbrio entre as duas áreas mais centrais do Instituto: a pesquisa e a produção. Outro fator de crise veio à luz na primeira gestão do herpetólogo Afrânio Amaral (1894-1982), que esteve na direção do Butantan entre março e setembro de 1921. Afrânio conseguiu retirar o Instituto da situação de crise, mas potencializou as tensões ao dirigi-lo com mãos de ferro e criticar publicamente seu antecessor. Suas críticas se inseriam num universo de conflitos entre interesses públicos e privados no campo da produção de imunobiológicos. Naquele momento, a indústria farmacêutica privada começava a entrar fortemente nesse ramo, sendo que vários pesquisadores das instituições públicas foram trabalhar em laboratórios privados. As divergências sobre os limites éticos que deveriam reger as relações entre as atividades científicas no setor público e no mercado privado, bem como a inexistência de regulação a esse respeito, possibilitaram o surgimento de conflitos relacionados, principalmente, à atuação dos técnicos dos institutos públicos em atividades privadas de produção de imunobiológicos (TEIXEIRA, 2001).

Vital Brasil retornou à direção do Butantan em 1924. No ano seguinte, a saúde pública paulista passou por uma reorganização, reunindo os institutos Butantan, Bacteriológico, Pasteur e Vacinogênico em uma só instituição como o nome de Instituto Butantan. Devido à reforma, o Butantan ampliou muito suas atividades de produção, que se elevaram ainda mais com o início da fabricação em larga escala da vacina contra a febre tifoide nos anos seguintes. $\mathrm{O}$ segundo período de Vital Brasil à frente do Instituto foi também marcado por uma ampliação das atividades de pesquisa, principalmente no campo da fisiologia. Na área da produção, iniciou-se o preparo da BCG, utilizada na proteção contra a tuberculose.

Em meados da década de 1920, o Butantan já se mostrava como uma instituição consolidada. Seus laboratórios realizavam pesquisas relacionadas a diversos 
campos das ciências biomédicas. Seu setor de produção elaborava diversos soros e vacinas utilizados pela saúde pública paulista. Um bom exemplo da importância da instituição para o Estado foi sua capacidade de ampliar a produção do soro antitetânico para atender às tropas envolvidas no combate ao movimento armado contra o governo Arthur Bernardes, que ficou conhecido como revolta tenentista de 1924. O mesmo ocorria em relação às doenças epidêmicas: quando em 1928 uma epidemia de varíola varreu o país, o Butantan ampliou a produção da vacina antivariólica chegando a fornecê-la para vários outros Estados (BENCHIMOL; TEIXEIRA, 1994).

Nos conturbados anos 1930, após o movimento armado que colocou Getulio Vargas no poder, o Butantan estava mais uma vez sob a administração de Afrânio Amaral, que havia retornado à direção do Instituto em 1928 com o objetivo de modernizar e ampliar ainda mais seu raio de ação. Em março de 1931, ele foi desmembrado dos outros institutos da saúde pública e colocado no organograma da recém-criada Secretaria da Educação e de Saúde Pública. Além disso, o Butantan adquiriu status de centro de medicina experimental, direcionado aos estudos de medicina humana e dos animais venenosos, e não mais centrado somente na produção de imunobiológicos. Os resultados dessas mudanças começaram a surgir quando diminuíram as instabilidades geradas pela Revolução Constitucionalista de 1932, que praticamente paralisou as instituiçôes públicas do Estado. Nos anos seguintes foi deflagrada uma política institucional de ampliação das atividades de pesquisa por meio da contratação de renomados pesquisadores estrangeiros, que, devido às crescentes tensões na Europa, onde se ampliavam as hostilidades contra os judeus, estavam dispostos a migrar para São Paulo. Em 1935 chegou ao Butantan o alemão Karl Heinrich Slotta (1895-1987) - conhecido pela descoberta do hormônio feminino, progesterona - para dirigir a seção de química e farmacologia experimentais. Em seguida foram contratados outros dois químicos, também alemães, da universidade de Breslau (hoje Vrotslav) para trabalharem como seus assistentes. Esse grupo conseguiu isolar uma proteína tóxica do veneno da cascavel e elaborar importantes estudos sobre a composição química do café. Para a recém-criada Seção de Genética veio outra cientista alemã, Gertrud van Übisch (1882-1965), que desenvolveria trabalhos sobre a genética do trigo. Além dos pesquisadores estrangeiros, vários renomados cientistas brasileiros, como o fisiologista Thales Martin (1896-1979) e o especialista em farmacologia José Ribeiro do Valle (1908-2000), ocuparam a direção das novas seções do Instituto, transformando-as em referência nestes campos de estudos no país. 
Apesar do grande desenvolvimento, o Instituto, neste período, passava por uma forte dissensão interna gerada com a implantação do regime de tempo de trabalho integral. A nova regra desagradou os pesquisadores, que também trabalhavam em laboratórios privados e foram impedidos de continuar a fazê-lo. Em 1936, a crise se agravou em virtude da abertura de um inquérito administrativo contra Afrânio Amaral, que era acusado de improbidade administrativa, e de uma campanha contra sua administração movida na Assembleia, pelo então deputado Adhemar de Barros (1901-1969), que era aliado político dos que se tornaram contrários a Afrânio Amaral em função da implantação do regime de tempo integral. No contexto de xenofobia e autoritarismo crescentes, gerados com a implantação do Estado Novo, os problemas do Butantan se ampliaram. No início de 1938, uma nova reforma da saúde pública criou o Departamento de Saúde do Estado e, mais uma vez, unificou os institutos biomédicos sob direção única. Um dos decretos que ultimavam essa reforma determinava que o cargo de diretor do Instituto Butantan seria de confiança do governo estadual. Nesse contexto, o próprio Adhemar de Barros, então alçado ao cargo de interventor no Estado, demitiu Afrânio Amaral.

Mais uma vez o instituto mergulhava num período de forte crise. Logo de início, os pesquisadores estrangeiros foram obrigados a deixarem seus cargos, por serem vistos pelo governo como uma ameaça à segurança nacional. Nos anos seguintes, vários inquéritos administrativos impediram o funcionamento de diversos setores. No cômputo geral, várias seções foram fechadas, a pesquisa foi reduzida e também a produção. Só para se ter uma ideia da gravidade do problema, entre 1938 e 1944, o Instituto Butantan teve mais de uma dezena de diretores, todos administrando a instituição por um curto espaço de tempo. Era o Estado Novo e suas funestas consequências para o Instituto. Neste período, os maiores esforços do Instituto relacionaram-se à guerra que ocorria na Europa. Assim, foi ampliada a produção de soros antidiftéricos e antitetânicos, que eram utilizados pelas tropas brasileiras na Itália, montada uma grande central de secagem de plasma sanguíneo para viabilizar a transfusão em larga escala e iniciado um projeto para fabricação de penicilina.

Com o processo de redemocratização iniciado em 1945, o Butantan parecia voltar a um período de tranquilidade. Na direção do Instituto o microbiologista Otto Bier (1906-1985) favoreceu o retorno do consenso sobre os caminhos a serem seguidos pelo Instituto e se empenhou para modernizar suas instalações e aparelhagens, que, em virtude do período de guerra, estavam muito defasadas, impedindo a elaboração de vários tipos de pesquisa e a produção em maior escala de imunobiológicos. 
Apesar desse curto intermezzo, a trajetória do Instituto voltaria a um contexto de crise a partir de 1947, quando o pesquisador Eduardo Vaz foi convidado para dirigi-lo. Sua gestão pautou-se pela crítica à separação das atividades de pesquisa e produção. Egresso da indústria farmacêutica privada, ele acreditava que a pesquisa só deveria ter lugar num instituto quando fosse a base para a produção, e que o Butantan deveria ter como objetivo central a fabricação de produtos para a saúde pública. Para colocar suas diretrizes em ação, Vaz obteve do governo estadual uma nova reforma nos estatutos do Butantan, que passaram a limitar suas atividades à preparação de imunobiológicos para a defesa sanitária e aos estudos sobre animais peçonhentos. Em conformidade com essa nova orientação, vários laboratórios foram fechados ou transferidos para outras instituiçōes. De forma semelhante, muitos pesquisadores deixaram o Instituto, ou levaram suas investigaçōes para a Universidade de São Paulo ou para a Escola Paulista de Medicina. Tais diretrizes foram impostas de forma extremamente autoritária e acabaram por violentar a tradição de pesquisa da instituição, fazendo-a mais uma vez mergulhar em uma crise (TEIXEIRA, 2001).

A segunda metade do século XX marca o fim dos grandes conflitos que até então dificultaram a trajetória do Instituto. Nos anos 1950, o Brasil vivia um momento de afirmação da ciência, que passava a ser vista como de importância estratégica para o país. Essa visão favorecia o consenso sobre a importância da pesquisa e do fortalecimento do setor público no campo da produção de imunobiológicos. Nesse contexto, o Butantan conseguiria consolidar sua vocação de Instituto de medicina experimental. Na década de 1960, o protagonismo do Instituto nas grandes campanhas de vacinação foi fundamental para o controle de doenças como a difteria, o sarampo e, principalmente, para sucesso da campanha nacional de erradicação da varíola. Na década seguinte, ele transformar-se-ia numa das instituiçôes principais do programa federal criado para intensificar o controle de doenças transmissíveis e ampliar a autossuficiência do país na produção de imunobiológicos, consolidando-se como instituição central na produção de imunobiológicos para a saúde pública nacional (TEIXEIRA, 2006).

\section{Referências bibliográficas}

BENCHIMOL, J.; TEIXEIRA, L. A. Cobras, lagartos \& outros bichos: uma história comparada dos institutos Oswaldo Cruz e Butantan. Rio de Janeiro: Fiocruz/Casa de Oswaldo Cruz/UFRJ, 1993. 
RIBEIRO, M. A. R. História sem fim... um inventário da saúde pública: São Paulo 18801930. São Paulo: Unesp, 1993.

TEIXEIRA, L. A. Repensando a história do Instituto Butantan. In: DANTES, M. A. (Org.). Espaços da Ciência: no Brasil 1800-1930. Rio de Janeiro: Editora da Fiocruz, 2001. p. 159-184. TEIXEIRA, L. A. Pesquisa biomédica e produção de imunobiológicos em São Paulo: um duelo entre o público e o privado. Cadernos de História Da Ciência, v. 2, n. 1, p. 105-123, 2006. Saúde, ciência e poder: sobre a trajectória do Instituto Butantan. Estudos do Século XX, Coimbra, v. 2, n. 5, p. 189-204, 2005. 


\section{Transcrição dos documentos}

São Paulo, 20 de novembro de 1899.

Caro amigo Oswaldo,

Desejo-te toda saúde e todo o bem estar de que é merecedor. Dirijo-te estas linhas para, de acordo com o que te prometi, dar-te notícias nossas e pedir-te que nos pagues na mesma moeda.

Regressei, como deves ter sabido, para S. Paulo, no dia 4 do corrente, trazendo algumas das minhas culturas, que pareceram-me em melhores condições. Aqui chegando meti-me logo em um trabalho insano e cruel, mui pouco apropriado ao meu estado de fraqueza. Foi uma imprudência de que me arrependo, porquanto o resultado foi ter de enfermar- me de novo por alguns dias. Hoje, felizmente, já estou melhor e desde ontem estive trabalhando.

Ainda não acabei o eu relatório, por ter sido interrompido por trabalhos de outra natureza.

Fiz experiências, em pequenos animais, ratos e cobaias, com as culturas que trouxe de Santos. Resultados magníficos. Ainda não concluí, entretanto, o estudo das culturas.

Como já deves saber, o Governo adquiriu a fazenda do Butantan, destinando-a para o Instituto Serumtherapico do Estado. Soube pelo Ribas, que vistes e apreciastes muito aquele local para instalação do Instituto, o que muito agradou-me pela autoridade de tua opinião.

Sou o encarregado do preparo do soro e quiçá da instalação do Instituto. Não sei se poderei com tamanha responsabilidade. Comecei a imunização de 4 cavalos pela injeção endovenosa de culturas mortas, até conseguirmos uma cocheira-enfermaria para os cavalos pestosos. Empregaremos então culturas virulentas.

A 1a injeção nos 4 cavalos correu bem. Apresentaram alguma reação que não durou muito tempo. Hoje, porém, ao fazermos a 2a injeção perdemos subitamente um dos animais, ao que parece de uma embolia.

Como vae o teu Instituto? Conta-me as tuas esperanças e auxilia-me com os teus sábios conselhos. Peço-te, com o maior empenho, que com a possível brevidade, me mandes a relação completa dos aparelhos, 
pequenos objetos e todo o material necessário para a instalação de um Instituto soroterápico.

Logo que tenhas o teu instituto montado irei até o Rio, pedir o auxílio de tuas luzes.

Abraça-te cordialmente o teu colega e amigo muito agradecido V. Brasil

(Dossiê Vital Brazil - 1899/1914 - Acervo Biblioteca Virtual Oswaldo Cruz - Fundação Oswaldo Cruz - Casa de Oswaldo Cruz - DAD)
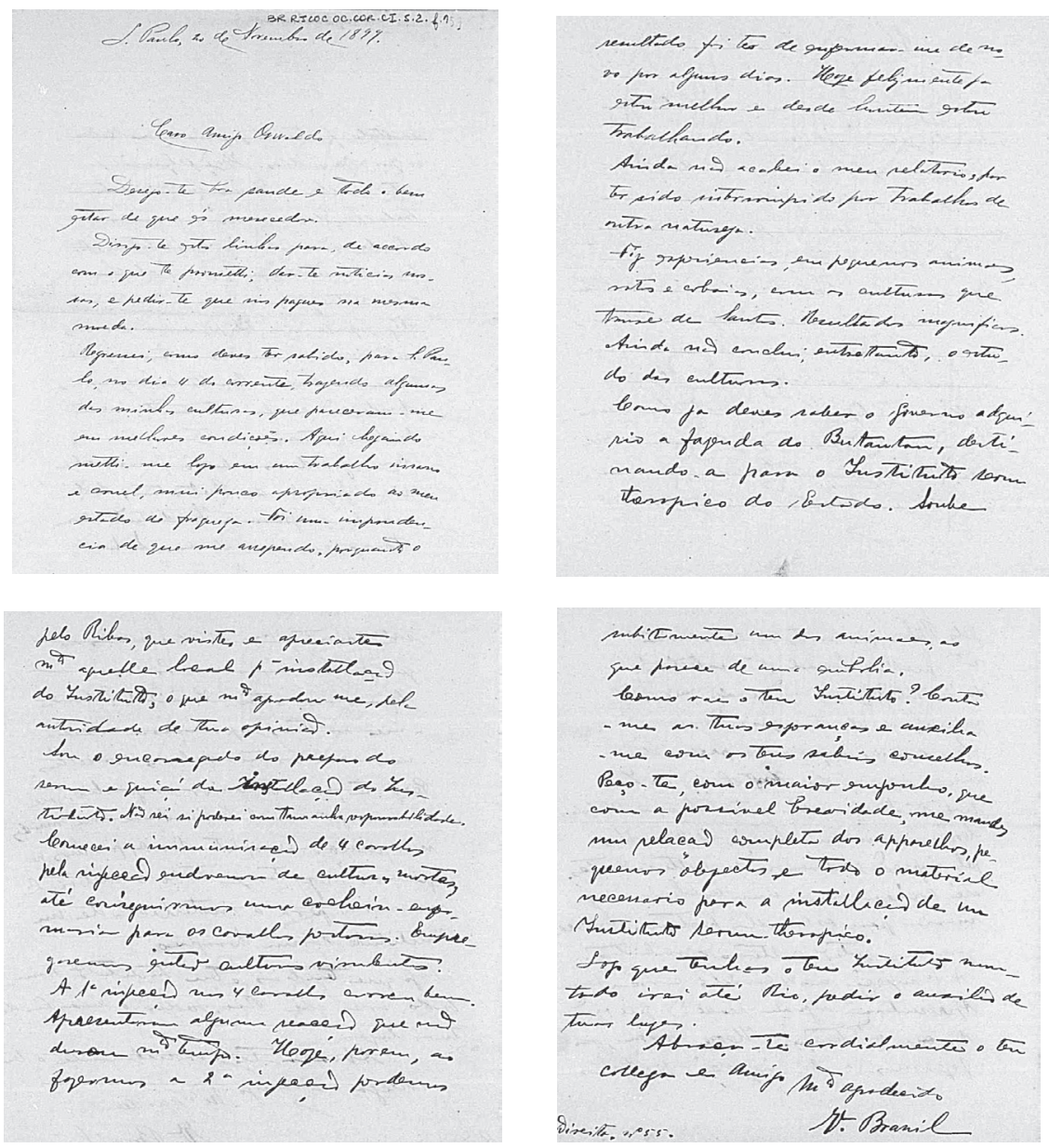
